\title{
Brain-Derived Neurotrophic Factor and Tyrosine Kinase Receptor B Involvement in Amygdala-Dependent Fear Conditioning
}

\author{
Lisa M. Rattiner, Michael Davis, Christopher T. French, and Kerry J. Ressler \\ Emory University School of Medicine, Center for Behavioral Neuroscience, Yerkes Research Center, Atlanta, Georgia 30329
}

\begin{abstract}
Brain-derived neurotrophic factor (BDNF) and its receptor, tyrosine kinase receptor B (TrkB), play a critical role in activity-dependent synaptic plasticity and have been implicated as mediators of hippocampal-dependent learning and memory. The present study is the first to demonstrate a role for BDNF and TrkB in amygdala-dependent learning. Here, the use of Pavlovian fear conditioning as a learning model allows us to examine the concise role of BDNF in the amygdala after a single learning session and within a well understood neural circuit. Using in situ hybridization, mRNA levels of six different trophic factors [BDNF, neurotrophin (NT) 4/5, NGF, NT3, aFGF, and $\mathrm{bFGF}$ ) were measured at varying time points during the consolidation period after fear conditioning. We found temporally specific changes only in BDNF gene expression in the basolateral amygdala after paired stimuli that supported learning but not after exposure to neutral or aversive stimuli alone. Using Western blotting, we found that the Trk receptor undergoes increased phosphorylation during this consolidation period, suggesting an activation of the receptor subsequent to BDNF release. Furthermore, disruption of neurotrophin signaling with intra-amygdala infusion of the Trk receptor antagonist K252a disrupted acquisition of fear conditioning. To address the specific role of the TrkB receptor, we created a novel lentiviral vector expressing a dominant-negative TrkB isoform (TrkB.T1), which specifically blocked TrkB activation in vitro. In vivo, TrkB.T1 lentivirus blocked fear acquisition without disrupting baseline startle or expression of fear. These data suggest that BDNF signaling through TrkB receptors in the amygdala is required for the acquisition of conditioned fear.
\end{abstract}

Key words: BDNF; TrkB; amygdala; fear conditioning; neurotrophins; NGF; FGF; NT4/5; lentivirus

\section{Introduction}

The neurotrophin brain-derived neurotrophic factor (BDNF) plays a diverse role in regulating neuronal structure and function in both the developing and adult CNS (Barde et al., 1987; Leibrock et al., 1989). Increasing evidence indicates that the synthesis, secretion, and actions of BDNF on synaptic transmission are regulated by neuronal activity and that BDNF itself can acutely modify synaptic efficacy (Thoenen, 1995; Katz and Shatz, 1996; Black, 1999; McAllister et al., 1999; Poo, 2001). Given its well established role in functional synaptic plasticity and its ability to induce changes in synaptic morphology, BDNF has become an attractive candidate as a molecular mediator of learning and memory.

Research on the role of BDNF in learning and memory has focused almost exclusively on hippocampal long-term potentiation (LTP) and behavioral tasks that are dependent on the hip-

Received Dec. 22, 2003; revised Feb. 23, 2004; accepted Feb. $27,2004$.

This research was supported by a Rockefeller Brothers Fund Culpeper Scholarship in Medical Sciences, the National Alliance for Research on Schizophrenia and Depression, the Science and Technology Center Program (Center for Behavioral Neuroscience) of the National Science Foundation under Agreement IBN-987675, and grants from the National Institute of Mental Health.

Correspondence should be addressed to Dr. Kerry J. Ressler, Center for Behavioral Neuroscience, Emory University School of Medicine, Yerkes Research Center, 954 Gatewood Drive, Atlanta, GA 30329. E-mail: kressle@emory.edu. DOI:10.1523/JNEUROSCI.5654-03.2004

Copyright $\odot 2004$ Society for Neuroscience $\quad$ 0270-6474/04/244796-11\$15.00/0 pocampus. Despite the multiple lines of evidence that BDNF and its receptor, tyrosine kinase receptor B (TrkB), are involved in synaptic plasticity, a definitive role for these molecules in behavioral models of learning and memory has been difficult to demonstrate for a number of reasons. Although hippocampal circuits are quite plastic and clearly involved in learning and memory, the contribution of these circuits to the behaviors under study is often unclear (Barnes, 1995). Additionally, because of limited pharmacological tools and the spatial and developmental limitations of genetically modified animals, a clear causal function for TrkB in behaviorally relevant learning paradigms has been difficult to establish (Knusel and Hefti, 1992; Linnarsson et al., 1997; Minichiello et al., 2002).

The homodimerization of tyrosine kinase receptors makes them particularly amenable to study with dominant-negative truncated recombinant proteins (Klein et al., 1991; Jing et al., 1992). Specifically, it has been shown previously that removal of the cytoplasmic tail of the TrkB receptor leads to specific inhibition of normal TrkB functioning (Saarelainen et al., 2000; Haapasalo et al., 2001). The experiments in the current study use virally mediated dominant-negative inhibition of TrkB in a spatially and temporally discrete manner to evaluate the role for TrkB in the acquisition and consolidation of fear memory.

The well described circuitry of the amygdala combined with well defined and easily controlled sensory components that are 
tightly coupled to the expression of the learned fear response makes it an excellent model system to evaluate the role of intracellular processes in learning and memory (Davis, 1992; Fanselow and LeDoux, 1999; Schafe et al., 1999; LeDoux, 2000; Maren, 2001; McGaugh, 2002; Ressler et al., 2002). Despite these advantages, the involvement of trophic factors in amygdaladependent learning and memory has yet to be examined.

This study demonstrates a role for BDNF in amygdaladependent fear conditioning. Our findings suggest that production of BDNF mRNA in the amygdala is regulated by neuronal activity during fear conditioning. Fear conditioning also results in activation of the Trk receptor in the amygdala. In addition, Trk receptor blockade with $\mathrm{K} 252 \mathrm{a}$ or viral expression of a dominantnegative TrkB receptor impairs amygdala-dependent learning and memory as assessed by fear-potentiated startle (FPS).

\section{Materials and Methods \\ Animals}

A total of 161 male Sprague Dawley rats (Charles River, Raleigh, NC), weighing between 300 and $400 \mathrm{gm}$, were maintained on a $12 \mathrm{hr}$ light/dark cycle (lights on at 8:00 A.M.) with food and water available ad libitum. Rats were group housed in $45 \times 24 \times 20 \mathrm{~cm}$ polycarbonate cages (four rats per cage) and individually housed after surgery in $20 \times 19 \times 24 \mathrm{~cm}$ hanging wire mesh cages. All procedures were in accordance with the NIH Guide for the Care and Use of Laboratory Animals and were approved by the institutional animal care and use committee of Emory University.

\section{Fear conditioning apparatus}

Animals were trained and tested in four identical $8 \times 15 \times 15 \mathrm{~cm}$ Plexiglas and wire mesh cages as described previously (Cassella et al., 1986; Walker and Davis, 2000). Cage movement was measured by an accelerometer, the analog output of which was amplified and digitized. Startle amplitude (reported in arbitrary linear units) was defined as the maximal peak-to-peak accelerometer voltage (integrated as velocity) that occurred during the first $200 \mathrm{msec}$ after the onset of the startle-eliciting stimulus. Background white noise $(60 \mathrm{~dB}$ wideband $)$ was delivered through high-frequency speakers. Startle responses were evoked by 50 msec, $95 \mathrm{~dB}$ white noise bursts $(0-22 \mathrm{kHz})$ delivered through the same speakers. The unconditioned stimulus (US) was a $0.5 \mathrm{sec}, 0.4 \mathrm{~mA}$ footshock delivered through the cage floor bars. The visual conditioned stimulus (CS) for training and testing was a 4 sec light ( 82 lux) produced by an $8 \mathrm{~W}$ fluorescent bulb (100 $\mu \mathrm{sec}$ rise time) located $10 \mathrm{~cm}$ behind each cage. The odor CS was 5\% amyl acetate (Sigma, St. Louis, MO) diluted in propylene glycol. This odor was delivered for $4 \mathrm{sec}$ through an olfactometer (model E15-03; Coulbourne Instruments, Allentown, PA) mounted outside the sound-attenuating chamber as described previously (Paschall and Davis, 2002). The presentation and sequencing of all stimuli were under the control of the Macintosh G3 computer using custom-designed software.

\section{Behavioral procedures}

Acclimation. Animals were pre-exposed to handling and placement in the training-testing chamber for $5 \mathrm{~d}$ before fear conditioning. On day 3 of pre-exposure, baseline startle was measured by presenting 30 startle stimuli at a $30 \mathrm{sec}$ interstimulus interval (ISI). Animals were then divided into matched experimental groups with equivalent mean startle amplitudes.

Experiment 1. Twenty-four hours after the last acclimation session, animals were placed in the conditioning chambers as before. In the odorshock paired group $(n=10), 10$ odor-shock pairings were given with an average intertrial interval (ITI) of 4 min (range, 3-5 min), creating a 40 min training session. The shock (US) was delivered during the last $0.5 \mathrm{sec}$ and coterminated with the 4 sec odor (CS). A context control group ( $n=$ 2) was placed in the chamber for $40 \mathrm{~min}$ without odor or shocks and killed $2 \mathrm{hr}$ after context exposure. Four animals from the odor-shock paired group were kept for behavioral testing that occurred $48 \mathrm{hr}$ later, and six animals from this group were killed at different time points after fear conditioning for in situ analysis ( $n=2$ per time point). A completely naive control group $(n=2)$ was killed from their home cages in the animal housing facility. To further examine the $2 \mathrm{hr}$ time point, a second group of animals were trained with 15 light-shock pairings (trained; $n=$ 6), as described in the next section, and killed $2 \mathrm{hr}$ after training or killed directly from their home cage (control; $n=6$ ).

Experiment 2. In the light-shock paired group $(n=16), 15$ light-shock pairings were given with an average ITI of $2.5 \mathrm{~min}$ (range, 2-3 min), creating a $40 \mathrm{~min}$ training period. The shock (US) was delivered during the last $0.5 \mathrm{sec}$ and coterminated with the $4 \mathrm{sec}$ light (CS). The light-alone control group ( $n=14)$ received $15,4 \mathrm{sec}$ light presentations, with an average ITI of $2.5 \mathrm{~min}$ (range, 2-3 $\mathrm{min}$ ), over a $40 \mathrm{~min}$ training period. The shock-alone group $(n=14)$ received $15,0.5 \mathrm{sec}$ shocks, with an average ITI of $2.5 \mathrm{~min}$ (range, $2-3 \mathrm{~min}$ ), over a $40 \mathrm{~min}$ training session. Animals from all groups $(n=44)$ were returned to their home cages after training and killed $2 \mathrm{hr}$ later for in situ hybridization $(n=16)$ and Western blot analysis $(n=16)$. Twelve animals were kept for behavioral testing $48 \mathrm{hr}$ later.

K252a experiment. Immediately after infusions, animals $(n=32)$ were placed in the conditioning chambers and after 5 min were presented with 15 light-shock pairings, with an ISI of $4 \mathrm{~min}$ (range, 3-5 min). The shock (US) was delivered during the last $0.5 \mathrm{sec}$ and coterminated with the $4 \mathrm{sec}$ light (CS).

Acquisition experiment: lentivirus. Animals $(n=36)$ were infused with lentivirus and $12 \mathrm{~d}$ later placed in conditioning chambers. After a $5 \mathrm{~min}$ acclimation period, animals received 15 light-shock pairings with an average ITI of $2.5 \mathrm{~min}$ (range, $2-3 \mathrm{~min}$ ), creating a $40 \mathrm{~min}$ training session. The shock (US) was delivered during the last $0.5 \mathrm{sec}$ and coterminated with the $4 \mathrm{sec}$ light (CS). This same training was then repeated $24 \mathrm{hr}$ later. After the second training session, animals were returned to their home cages and kept for behavioral testing that occurred $48 \mathrm{hr}$ later.

Performance experiment: lentivirus. Animals $(n=23)$ were cannulated and allowed $12 \mathrm{~d}$ to recover. The rats were then trained using 15 lightshock pairings on each of $2 \mathrm{~d}$. Two minutes after the last CS-US pairing on day 1 of training, animals were given a short FPS test consisting of 10 test trials. For five of these test trials, a startle-eliciting noise burst ( $95 \mathrm{~dB}$ ) was presented $3.2 \mathrm{sec}$ after onset of the light CS (i.e., light-startle trials). For the other five trials, noise bursts were presented in the dark (i.e., startle-alone trials). The two trial types were presented in a balanced mixed order. For each rat, a difference score (mean startle amplitude on light-startle trials minus mean startle amplitude on startle-alone trials) was calculated. On the basis of these results, rats receiving pretest infusions of virus were assigned to treatment groups such that each group [lenti-TrkB.T1, $n=11$; lenti-green fluorescent protein (GFP), $n=12$ ] had comparable mean levels of FPS (i.e., difference scores). Four days later, animals were given bilateral intra-amygdala injections of either lenti-TrkB.T1 or lenti-GFP through the previously implanted cannulas and returned to their home cages for a minimum of $9 \mathrm{~d}$ (i.e., to allow full infection of the virus).

Behavioral testing. After a $5 \mathrm{~min}$ acclimation period, animals were presented with 30 startle stimuli $(95 \mathrm{~dB}$ ) at a $30 \mathrm{sec}$ ISI (leader stimuli), followed by 30 startle-alone test trials and 30 intermixed CS-startle test trials. Throughout these procedures, startle stimuli were presented at an ISI of $30 \mathrm{sec}$.

Statistical analyses. Difference scores (mean startle amplitude on lightstartle trials minus mean startle amplitude on startle-alone trials) were analyzed by ANOVA followed by Tukey's post hoc planned comparisons, ANOVA with repeated measures, two-way ANOVA, paired $t$ tests (within-group comparisons), or $t$ tests for independent samples (between-group comparisons). For all comparisons, the criterion for significance was $p \leq 0.05$.

\section{Surgery and infusions}

K252a experiments. Rats were anesthetized with sodium pentobarbital $(50 \mathrm{mg} / \mathrm{kg}$, i.p.) and placed in a stereotaxic frame with the nose bar set to $-3.8 \mathrm{~mm}$ (flat-skull position). The skull was exposed, and 22 gauge guide cannulas (Model C313G, Plastic Products, Roanoke, VA) were lowered bilaterally into the basolateral amygdala (BLA) (anteroposterior $=-3.3$, dorsoventral $=-8.2$, mediolateral $=+5.4$ from bregma). Dummy cannulas (Model C313DC/1, Plastic Products) were inserted into each guide 
cannula to prevent clogging. The tip of each dummy cannula extended $\sim 1 \mathrm{~mm}$ past the end of the guide cannula. Jeweler screws were anchored to the skull, and the entire assembly was cemented in place using Cranioplastic Power (Plastic Products). At least 10 d elapsed between surgery and the behavioral procedures. Immediately before and immediately after training, rats were infused with either K252a (Calbiochem, La Jolla, CA) $(25 \mathrm{ng}, 50 \mu \mathrm{M})(n=17)$ diluted in artificial CSF (ACSF)/50\% DMSO or ACSF/50\% DMSO (vehicle, $n=15$ ); $0.5 \mu \mathrm{l}$ infusions were made through 28 gauge injection cannulas (Model C313I, Plastic Products) that were attached by polyethylene tubing to a Hamilton microsyringe. Infusions were performed at a rate of $0.25 \mu \mathrm{l} / \mathrm{min}$, and injection cannulas were left in place for $2 \mathrm{~min}$ after the infusion was completed.

Acquisition experiment: lentivirus. Rats were anesthetized and placed in a stereotaxic frame, and a Hamilton microsyringe was lowered to the same coordinates as described for the cannulas above. Injections were performed with a $10 \mu \mathrm{l}$ Hamilton microsyringe (22 gauge beveled-tip needle) that was coated with $1 \%$ BSA before virus loading. Animals received bilateral injections of lentivirus; $2 \mu$ l of virus per side were injected at a rate of $0.2 \mu \mathrm{l} / \mathrm{min}$ (UltramicropumpII, World Precision Instruments, Sarasota, FL). The needle was left in place for $10 \mathrm{~min}$ after the injection, and the skin was closed using a 6-0 Vicryl suture (Ethicon, Johnson \& Johnson, Piscataway, NJ). At least 9 d elapsed between surgery and behavioral procedures.

Performance experiment: lentivirus. Rats were cannulated as described above. Bilateral intra-amygdala injections of either lenti-TrkB.T1 or lenti-GFP were made through the previously implanted cannulas. Two microliter infusions of virus were performed at a rate of $0.25 \mu \mathrm{l} / \mathrm{min}$, and injection cannulas were left in place for $10 \mathrm{~min}$ after the infusion was completed. The rats were then returned to their home cages for a minimum of $9 \mathrm{~d}$ (i.e., to allow full infection of the virus).

Preparation of riboprobes and in situ hybridization. The full-length clones used for experiments 1 and 2 were obtained as expressed sequence tag clones from the NIH IMAGE database (ATCC, Manassas, VA): NGF in pCMV-SPORT6 (GI: 11520539), neurotrophin (NT) 4/5 in pCMVSPORT6 (GI: 9764281), NT3 in pT7T3D (GI: 1793906), aFGF in pT7T3D (GI: 1476960), bFGF in T7T3D (GI: 3687118), and BDNF in pT7T3D (GI: 3837569). In situ hybridization was performed with antisense riboprobes after sequence verification of the clones. All clones analyzed were $>90 \%$ homologous with rat coding sequence as determined by National Center for Biotechnology Information basic local alignment search tool. In situ hybridization was performed as follows. Rats were killed by chloral hydrate overdose after fear conditioning and perfused intracardially with $4 \%$ paraformaldehyde in PBS. Brains were fixed overnight, rinsed with PBS, allowed to equilibrate at $4^{\circ} \mathrm{C}$ in $20 \%$ sucrose/PBS, and then rapidly frozen in dry ice and stored at $-80^{\circ} \mathrm{C}$. Brains were sectioned at $16 \mu \mathrm{m}$ thickness on a Leica Cryostat (Nussloch, Germany) at $-20^{\circ} \mathrm{C}$ onto gelatin-coated slides. Sections were placed on 20 consecutive slides per brain, such that each slide contained similar sections of brain from three different anatomic areas (anterior commissure, anterior amygdala, and posterior amygdala), thus creating 20 identical sets of slides. In situ hybridization was performed as described previously (Sassoon et al., 1988). [ $\left.{ }^{35} \mathrm{~S}\right] \mathrm{UTP}(1250 \mathrm{Ci} / \mathrm{mmol}, 12.5 \mathrm{mCi} / \mathrm{ml}$; DuPont NEN, Boston, MA)-labeled riboprobes were prepared from linearized clones using T7 or T3 polymerase at high specific activity by only using radioactive UTP in the polymerase reaction, with $\sim 20 \%$ incorporation. After preparation of full-length antisense RNA strands, the RNA was base hydrolyzed to average lengths of 50-100 bp and isolated using a Sephadex gravity flow column. Hybridizations were performed under Parafilm at $52^{\circ} \mathrm{C}$ overnight. Slides were then stringently washed, dried, and placed against Kodak (Rochester, NY) magnetic resonance autoradiography film for $1-5 \mathrm{~d}$.

Films were scanned into a desktop computer at $600 \mathrm{dpi}$, and images were analyzed with Adobe Systems (San Jose, CA) Photoshop software. Hybridization density quantification was performed with the mean luminosity histogram feature of Adobe Photoshop. This measure was shown to produce linear densities with ${ }^{14} \mathrm{C}$ radiation standards with the exposure times and levels used. Within one experiment, all slides hybridized to the same probe were exposed to the same piece of film. This ensured equivalent exposure times and conditions between animals and experimental groups. For each section, hybridization density was determined for the regions of interest (ROI), as well as an adjacent background area that lacks hybridization (e.g., internal capsule). For each section, normalized density $=($ ROI density - background density $)$. The normalized densities from two different cryostat sections per brain were examined and averaged to give the density for each individual per ROI. For each experimental group, hybridization density is reported as the average density of all individual animals for that condition \pm SEM. Comparison of means between experimental groups was performed with ANOVA followed by a post hoc Tukey's test using the SPSS (Chicago) statistics package.

\section{Immunocytochemistry and immunoblotting}

Brain sections $(16 \mu \mathrm{m})$ on slides (described above) were incubated with PBS and Triton X-100, blocked with normal goat serum, bovine serum albumin, and Triton X-100, and incubated in a 1:500 dilution of primary TrkB rabbit polyclonal antibody (SC-12, Santa Cruz Biotechnology, Santa Cruz, CA) overnight at $4^{\circ} \mathrm{C}$. Sections were then washed with PBS and bathed in a 1:500 dilution of secondary anti-rabbit biotinylated antibody $(\mathrm{Ab})$ for $2 \mathrm{hr}$. Avidin-biotin complexes were amplified using a standard Vectastain Elite ABC kit and visualized with diaminobenzidine $(\mathrm{DAB})$ peroxidase staining. Immunopositive cells were visualized using $\mathrm{NIH}$ image. All slides within a given experiment were processed together to ensure equivalent conditions between experimental groups and eliminate interassay variability.

Immunoblots were performed as follows. Rat amygdalas were rapidly dissected on ice, immediately frozen in crushed dry ice, and stored at $-80^{\circ} \mathrm{C}$. Samples were homogenized in $10 \mathrm{~mm}$ HEPES, $0.5 \mathrm{~mm}$ EDTA, and a protease inhibitor mixture (Roche Applied Sciences, Hertforshire, UK) using a Polytron homogenizer. Sample concentrations were determined with BSA standards, and equal amounts of protein $(20 \mu \mathrm{g}$ per sample) were added to each lane. Samples were prepared in $2 \%$ SDS, separated by SDS-PAGE, and electrophoretically transferred to polyvinylidene difluoride membranes (Osmonics). Membranes were blocked with $5 \%$ nonfat milk and $0.1 \%$ Tween in PBS for $30 \mathrm{~min}$ and probed with primary phospho-Trk Ab (Cell Signaling \#9140) overnight at $4^{\circ} \mathrm{C}$. Blots were washed and incubated with an HRP-conjugated secondary Ab for 2 $\mathrm{hr}$ at room temperature. Blots were visualized with enhanced chemiluminescence (Amersham Biosciences, Arlington Heights, IL) and quantified using Adobe Photoshop.

\section{Production and testing of recombinant lentiviral vectors}

Plasmid construction. Viral vectors are derived from the human immunodeficiency virus-based lentiviral backbones optimized by the laboratory of Dr. Didier Trono (University of Geneva, Geneva, Switzerland) (Naldini et al., 1996a). The lenti-GFP viral plasmid is the "pCMO2" vector, which was a generous gift from the laboratory of Dr. Joshy Jacob (Emory University, Atlanta, GA). pCMO2 was created by inserting the $1.4 \mathrm{~kb} \mathrm{BamHI-XhoI} \mathrm{fragment} \mathrm{containing} \mathrm{GFP-woodchuck} \mathrm{posttran-}$ scriptional regulatory element (WPRE) from the $\mathrm{pHR}^{\prime}$-cytomegalovirus (CMV)-GFP-WPRE plasmid (Zufferey et al., 1999) into BamHI-XhoI sites of the pHR-GFP-SIN backbone in place of the GFP fragment (Zufferey et al., 1999). The resulting pCMO2 lentivirus packaging vector contains a CMV promoter driving GFP expression followed by a WPRE.

The lenti-TrkB.T1 virus was constructed by first creating an epitopetagged TrkB.T1 construct. Clones for the full-length (FL) and truncated TrkB were a generous gift from Dr. Tony Hunter (The Salk Institute, San Diego, CA) (Middlemas et al., 1991). Using high-fidelity PCR, a BamHI site was inserted 5' of the initiation codon, and a nine amino acid hemagglutinin (HA) epitope tag encoding "YPYDVPDYA" was inserted immediately before the $3^{\prime}$ stop codon followed by an additional BamHI site and cloned into the PCR II-Topo cloning vector (Invitrogen, San Diego, $\mathrm{CA})$. After sequence verification, the $1.5 \mathrm{~kb} \mathrm{BamHI}$ fragment encoding the HA-tagged TrkB.T1 was inserted into the BamHI site of pCMO2 downstream of the CMV promoter. Clones were analyzed for directional orientation, followed by examination of membrane-bound expression of the TrkB.T1 protein using an anti-HA epitope tag Ab (MAB HA-7; Sigma) in transfected human embryonic kidney (HEK) 293 cells.

Preparation of viral stocks. Virus was generated by transient cotransfec- 
A

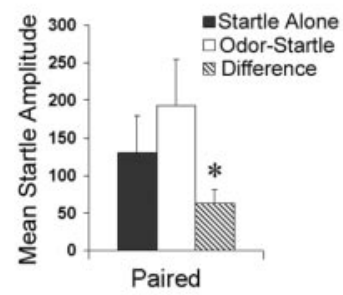

B

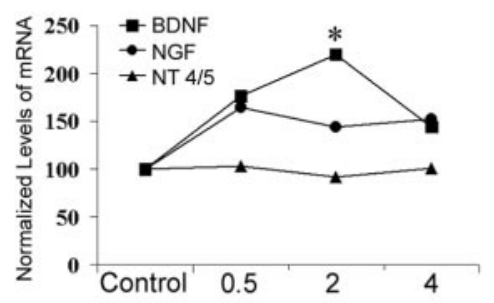

C

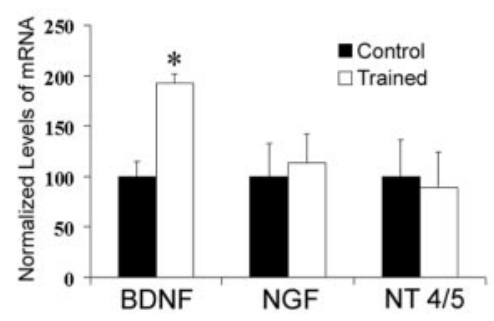

D

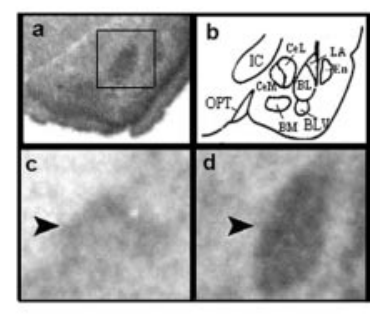

Figure 1. Temporal changes in neurotrophin gene expression after fear conditioning. A, Results of behavioral testing after olfactory fear conditioning. Animals were exposed to odor-shock pairings and tested $48 \mathrm{hr}$ later. Associative odor-shock pairings produced stable fear memories, as assessed by the fear-potentiated startle effect (paired $t$ test; ${ }^{*} p<0.05$ ). Mean startle amplitude (in arbitrary units) on startle-alone and odor-startle test trials and the difference between these two trial types are shown. $B$, Animals were trained using olfactory fear conditioning and killed 30 min, $2 \mathrm{hr}$, or $4 \mathrm{hr}$ after training. Relative levels of mRNA expression (in arbitrary units) normalized to control levels are shown for BDNF, NGF, and NT4/5 in the BLA. BDNF mRNA levels rise in the BLA and peak at $2 \mathrm{hr}$ after fear conditioning ( $t$ test; ${ }^{*} p<0.05$ ). These levels begin to return to baseline $4 \mathrm{hr}$ after conditioning (ANOVA; post hoc quadratic trend analysis; $p<0.05$ ). Levels of the other trophic factors do not significantly change during this time period. C, Further analysis of the $2 \mathrm{hr}$ time point shows that BDNF mRNA levels increase significantly in the BLA $2 \mathrm{hr}$ after fear conditioning ( $t$ test; ${ }^{*} p<0.01$ ), whereas levels of NGF and NT4/5 again do not change. D, In situ hybridization analysis of BDNF mRNA in the amygdala. Da, Region within the temporal lobe analyzed for BDNF mRNA hybridization density. Db, Schematic diagram from Paxinos and Watson (1997) of regions examined. Dc, Dd, Magnified images are shown of amygdala sections that have been hybridized with ${ }^{35}$ S-labeled antisense riboprobe and exposed to autodradiography film. BDNF mRNA levels rise in the BLA in animals after odor-shock pairings (Dd) but not in animals exposed to context only (Dc).

tion of the expression plasmid $(20 \mu \mathrm{g})$, VSV-G pseudotyping construct $(10 \mu \mathrm{g})$, and the packaging construct pCMV $\Delta \mathrm{R} 8.91(20 \mu \mathrm{g})$ into a 150 mm plate of $90 \%$ confluent HEK293T cells as described previously (Naldini et al., 1996b). Medium was collected 48 and $72 \mathrm{hr}$ after transfection, cleared of debris by low-speed centrifugation, and filtered through 0.45 $\mu \mathrm{m}$ filters. High-titer stocks were prepared by an initial ultracentrifugation for $1 \mathrm{hr}$ at 23,000 rpm (SW-28 rotor; Beckman Coulter, Palo Alto, $\mathrm{CA}$ ) and a secondary tabletop centrifugation at $13,000 \times \mathrm{g}$ for $30 \mathrm{~min}$. Viral pellet was resuspended in $1 \% \mathrm{BSA} / \mathrm{PBS}$ and stored at $80^{\circ} \mathrm{C}$. Viral titers were determined by infection of HEK293T cells. GFP-positive cells were visualized by fluorescent microscopy. TrkB.T1-positive cells were visualized by immunocytochemistry using an HA primary Ab (Sigma) and $\mathrm{DAB}$ visualization. After concentration, viral titers were $3 \times 10^{7}-$ $7 \times 10^{7}$ transducing units (TU) $/ \mathrm{ml}$.

PC12 differentiation assay. PC12 adrenal pheochromocytoma cells were propagated in collagen-coated T-flasks (BD-Biocoat) containing F12K medium with $10 \%$ fetal bovine serum and penicillin-streptomycin (ATCC). Cells at $30 \%$ confluence were transfected with $1 \mu \mathrm{g}$ each of TrkB.FL with or without lenti-TrkB.T1 using Lipofectamine 2000 (Invitrogen). BDNF (Calbiochem) or K252A were added $24 \mathrm{hr}$ after transfection at $50 \mathrm{ng} / \mathrm{ml}$ or $300 \mathrm{nM}$, respectively, and examined for BDNF-induced differentiation $72 \mathrm{hr}$ after the addition of BDNF. Results were tabulated as the average number of cells displaying neurite outgrowth per well.

\section{Results}

Time course of neurotrophin changes after fear conditioning We initially examined gene expression of six different trophic factors at several time points after olfactory fear conditioning to determine whether any of these were involved in fear learning and the time course over which they were regulated. After habituation to the experimental chambers, animals received odorshock pairings or no new stimuli (untrained context control). Odor-shock-trained animals were killed at several different time points after training ( $30 \mathrm{~min}, 2 \mathrm{hr}$, and $4 \mathrm{hr}$ ) or tested $48 \mathrm{hr}$ later for the presence of fear-potentiated startle (behavioral controls). All context control animals were killed $2 \mathrm{hr}$ after training. This 2 hr time point was selected on the basis of a previous experiment, suggesting that, for a large number of genes, the optimal time to observe changes in expression is $2 \mathrm{hr}$ after fear conditioning (Ressler et al., 2002). Animals that had experienced odor-shock pairings showed significant fear-potentiated startle, as demonstrated by an increase in the acoustic startle reflex in the presence versus absence of the odor (Fig. 1A, Odor-Startle vs Startle Alone) (paired $t$ test; $p<0.05$ ). Context control animals showed no appreciable difference between startle in the presence or absence of odor (Paschall and Davis, 2002).

The expression of six different trophic factor genes (NGF, BDNF, NT4/5, NT3, aFGF, and bFGF) was examined using in situ hybridization at three time points after fear conditioning compared with the untrained context control condition. Figure $1 B$ illustrates the temporal changes in BDNF, NGF, and NT4/5 gene expression in the BLA after olfactory fear conditioning. Baseline levels of NT3, aFGF, and bFGF were extremely low in the BLA and showed no appreciable differences after fear conditioning (data not shown). Only BDNF mRNA levels appeared to show activity-dependent changes after fear conditioning during the time periods examined. BDNF mRNA levels peaked in the BLA 2 $\mathrm{hr}$ after fear conditioning (Fig. $1 B$ ) (ANOVA: quadratic trend analysis; $\left.F_{(3,4)}=4.62 ; p<0.05\right)$. A post hoc $t$ test found a significant difference in BDNF mRNA expression in context controls versus $2 \mathrm{hr}$ time point ( $t$ test; $p<0.05$ ). This increase in BDNF mRNA in the BLA is illustrated in Figure $1 D$. These levels began to return to baseline $4 \mathrm{hr}$ after conditioning. Levels of the other trophic factors (NGF, NT4/5, NT3, aFGF, and bFGF) did not change significantly subsequent to conditioning. Levels of NGF mRNA did appear to increase slightly in the amygdala $30 \mathrm{~min}$ after conditioning; however, this change was not statistically significant ( $p$ ost hoc $t$ test; $p=0.6$ ).

To add statistical power to these results, we further examined levels of BDNF, NGF, and NT4/5 mRNA at the $2 \mathrm{hr}$ time point using a larger number of animals in each group. Animals were trained using light-shock pairings and killed $2 \mathrm{hr}$ after fear conditioning or killed directly from their home cage. Only BDNF $m R N A$ levels showed a statistically significant increase in the BLA $2 \mathrm{hr}$ after fear conditioning (Fig. 1C) ( $t$ test; $p<0.01$ ). Again, levels of NGF and NT4/5 did not change subsequent to fear conditioning.

\section{Selective induction of BDNF expression after associative fear conditioning}

The previous experiment suggested that there are temporally specific changes in BDNF gene expression after fear conditioning. To further examine this change, we sought to replicate the results of experiment 1 using additional control groups, a single time point, and a different CS modality. Our time course results suggested that the optimal time to observe changes in BDNF gene expression is $2 \mathrm{hr}$ after fear conditioning; thus this time point was chosen for all further experiments. 


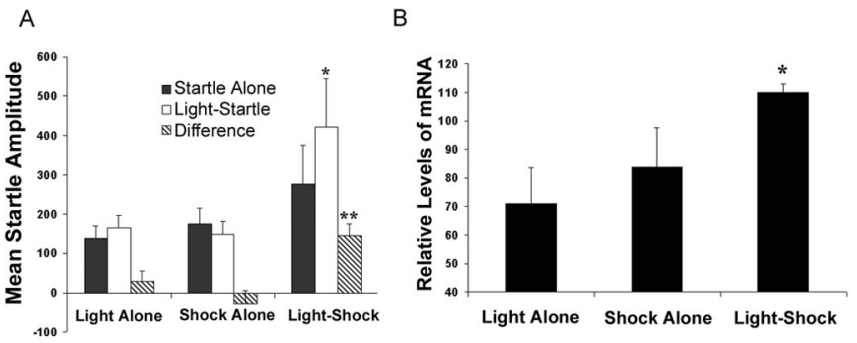

Figure 2. Changes in BDNF gene expression after light-shock fear conditioning. $A$, Results of behavioral testing after the light-alone, shock-alone, and light-shock training. Light-shock pairings produced stable fear memories in the light-shock associative group, as assessed by the fear-potentiated startle effect (paired $t$ test; ${ }^{*} p<0.05$ ). Light-alone and shock-alone control groups show no appreciable difference between startle in the absence or presence of the light. The difference scores for the light-shock group are significantly different from the difference scores for the light-alone or shock-alone controls (ANOVA; ${ }^{* *} p<0.05$ ). B, In situ hybridization analyses of BDNF in the BLA after light-alone, shock-alone, or light-shock presentation. BDNF mRNA expression in the BLA changed significantly across the three groups (ANOVA; ${ }^{*} p<0.05$ ).

After handling and habituation, animals were trained using 15 light-shock pairings, 15 light presentations alone, or 15 shock presentations alone. Fifteen CS-US pairings were used as opposed to the 10 CS-US pairings in the previous experiment because the visual CS is not as behaviorally relevant as an odor CS to the rodent and thus requires more training trials to achieve the same levels of fear (Paschall and Davis, 2002). Light-shock, lightalone, and shock-alone animals were killed $2 \mathrm{hr}$ after training or tested $24 \mathrm{hr}$ later for the presence of fear-potentiated startle (behavioral controls). Animals that had experienced light-shock pairings showed significant fear-potentiated startle (Fig. 2A) (paired $t$ test; ${ }^{*} p<0.05$ ). Animals that had received light-alone or shock-alone training showed no appreciable difference between startle in the presence or absence of light. An ANOVA indicated a significant between-group difference (Fig. $2 A$ ) (ANOVA: $F_{(2,9)}=$ 11.5 ; $^{* *} p<0.05$ ) and a post hoc multiple comparisons (Tukey's) test indicated that the light-shock group showed significantly more fear-potentiated startle than either light-alone or shockalone controls $(p<0.05)$.

Animals were killed $2 \mathrm{hr}$ after fear conditioning, and brains were prepared for in situ hybridization analysis with the probes described above. We found significant between-group differences in levels of BDNF mRNA expression in the BLA after fear conditioning (Fig. $2 B$ ) (ANOVA: $F_{(2,10)}=5.02 ; p<0.05$ ), with a significant fit to a linear trend $\left(F_{(1,10)}=5.22 ; p<0.05\right)$. A post hoc Tukey's test found a significant difference between the lightshock and light-alone groups. This experiment confirms our previous findings that BDNF gene expression appears to show activity-dependent changes after associative fear conditioning but not after exposure to an equal number of CS-alone or USalone presentations. These data suggest that an increase in BDNF mRNA occurs during fear learning, regardless of the CS modality.

To ensure that our observed increase in BDNF mRNA was selective to the basolateral complex of the amygdala, we analyzed levels of BDNF mRNA in other brain regions after light-shock, light-alone, and shock-alone exposure. The medial nucleus of the amygdala (MeA), ventral posteromedial nucleus of the thalamus (VPM), and dorsal hippocampus [including dentate gyrus (DG), CA1, and CA3] were examined from the same sections used to analyze BDNF mRNA in the BLA. We found that for all three of the regions analyzed there was no significant change in BDNF mRNA levels across the three groups, as analyzed by ANOVA (Fig. 3) (hippocampus: $F_{(2,10)}=0.07, p=0.9$; VPM: $F_{(2,10)}=$

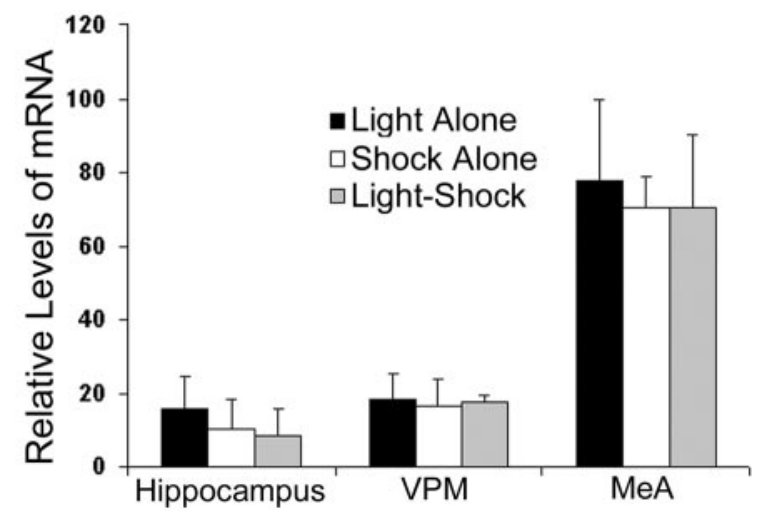

Figure 3. Anatomical specificity of BDNF signal. In situ hybridization analyses of $B D N F$ in the MeA, VPM, and hippocampus (DG, CA1, CA3) 2 hr after light-shock, light-alone, and shock-alone exposure. There were no changes in BDNF mRNA in any of these regions across the three groups.

A TrkB Protein

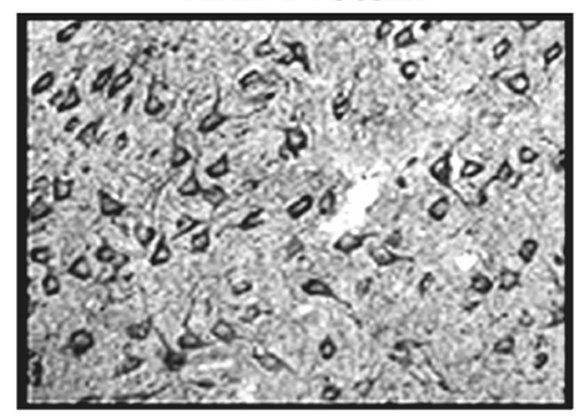

B

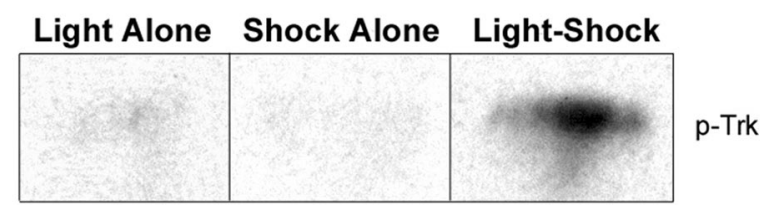

Figure 4. Changes in levels of phosphorylated-Trk receptor protein in the amygdala after fear conditioning. $A$, Immunohistochemical analysis of TrkB immunoreactivity (high power) in the amygdala. $B$, Representative Western blots of amygdala samples probed with phosphorylated-Trk Ab. Samples were taken from animals that had been exposed to light presentations alone, shock-alone, or light-shock pairings.

$\left.0.02 ; p=1.0, \mathrm{MeA}: F_{(2,10)}=0.2, p=0.8\right)$. These results suggest that the increase in BDNF mRNA in the BLA after light-shock pairings is relatively selective to this region and does not occur in all places where there is basal BDNF gene expression. Of note, it is known that BDNF within the hippocampus is involved in contextual learning (Hall et al., 2000). In our experiments, we explicitly examined cue learning and not context learning by preexposing animals to the context for multiple days before cue conditioning. Previous behavioral experiments have shown that the hippocampus is not involved in such cue-specific fear conditioning (Phillips and LeDoux, 1992).

\section{The Trk receptor is activated within the amygdala with fear conditioning}

Next we examined the receptor mechanisms related to the increase in BDNF gene expression. The presence of TrkB receptors in the amygdala, as well as the pattern of staining in the BLA, was first established using immunohistochemistry. Immunohisto- 

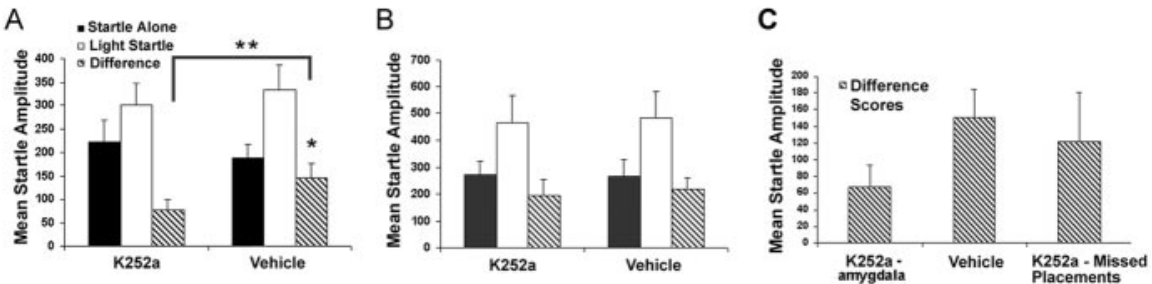

Figure 5. Effect of K252a, a nonselective Trk receptor antagonist, on acquisition of fear conditioning as assessed by fearpotentiated startle. Filled bars represent startle response to startle-alone trials, white bars represent startle response to lightstartle trials, and hatched bars represent difference scores. A, Rats received bilateral intra-amygdala infusions of ACSF (vehicle) or K252a immediately before and immediately after light-shock fear conditioning (training) and were tested $48 \mathrm{hr}$ later. Vehicleinfused rats showed fear-potentiated startle during testing ( $t$ test; ${ }^{*} p<0.05$ ) that was not seen in the K252a-infused rats. Mean difference scores of K252a-infused animals were significantly lower than difference scores of vehicle-infused animals ( $t$ test; $\left.{ }^{* *} p<0.05\right)$. This difference was not accounted for by a change on the startle-alone trials because there was no significant difference between groups on the startle-alone trials. $B$, Deficits produced by pretraining infusions of K252a did not impair future acquisition of fear learning. Rats that had previously received vehicle or K252a were retrained without infusions $10 \mathrm{~d}$ after the initial training and testing sessions and retested $48 \mathrm{hr}$ after retraining. An ANOVA with repeated measures showed a significant fear-potentiated startle effect by trial type (ANOVA; $p \leq 0.05$ ) but no trial-by-group interaction; thus the previously observed deficits could not be attributed to permanent amygdala damage. C, K252a demonstrates anatomical specificity. Mean difference scores of animals receiving intra-amygdala infusions of K252a or vehicle and animals receiving K252 infusions outside of the amygdala. Rats that received K252a infusions in areas outside of the amygdala showed levels of fear-potentiated startle equivalent to those of animals infused with ACSF.

chemical analysis showed a large number of intensely stained TrkB-immunoreactive neurons within the BLA. These results suggest that this receptor is indeed present and in sufficient quantity within the BLA to respond to BDNF (Fig. 4A).

To examine the activation of neurotrophin receptors with amygdala-dependent fear conditioning, we analyzed phosphorylation of the Trk receptor. Tissue was obtained from the lightshock experiment described above in which animals were killed 2 hr after fear conditioning. Western blots were used to examine levels of phospho-Trk receptors in the BLA after fear conditioning or control exposures (Fig. 4B). Quantitative densitometric analysis of Western blots probed for phospho-Trk receptors showed significantly elevated levels of phospho-Trk after associative light-shock pairings but not light-alone or shock-alone presentations (relative levels of protein expressed as a function of mean luminosity: light alone $=12$; shock alone $=2.0$; lightshock $=45)\left(\right.$ ANOVA: $\left.F_{(2,13)}=4.31 ; p<0.05\right)$. Notably, total levels of Trk protein within the amygdala did not change at this time point ( $p>0.5$; data not shown).

\section{Blockade of neurotrophin action by K252a impairs fear-conditioned learning}

If BDNF or other Trk-activating ligands are required for fear conditioning, then infusions of a Trk receptor antagonist should impair this process. $\mathrm{K} 252 \mathrm{a}$ is a potent inhibitor of the tyrosine kinase activity of neurotrophin receptors and is the most widely used pharmacological Trk receptor antagonist (Tapley et al., 1992). Animals received bilateral infusions of either K252a (25 ng) (Jiang et al., 2001) or ACSF into the BLA immediately before and after training. Infusion of $\mathrm{K} 252 \mathrm{a}$ resulted in impairment in fear-conditioned learning when animals were tested, drug free, $48 \mathrm{hr}$ later. Mean startle amplitude on startle-alone and on lightstartle test trials, and the difference between these two trial types, are shown for each group in Figure 5A. Mean difference scores of K252a-infused animals were significantly lower than difference scores of ACSF-infused animals $\left(t\right.$ test; $\left.{ }^{\star *} p<0.05\right)$. This difference was not accounted for by a change in the startle-alone trials because there was no significant difference between groups on the startle-alone trials.
To determine whether the effects of K252a might reflect permanent damage to the amygdala rather than an acute drug effect, animals that had previously received K252a or ACSF were retrained $10 \mathrm{~d}$ after the initial training session and retested. Animals were not infused for this retraining session. An ANOVA with repeated measures showed a significant fearpotentiated startle effect by trial type $\left(F_{(1,26)}=30.0 ; p \leq 0.05\right)$ but no trial by group interaction (Fig. $5 B$ ). These results indicate that, collapsed across groups, all animals showed fear-potentiated startle. Closer examination indicated that both K252a and vehicle groups show statistically significant fear-potentiated startle (paired $t$ test; $p<0.05$ ). Together these data suggest that both groups were capable of learning the CS-US association and that K252a did not cause permanent amygdala damage. Placements for all animals whose behavioral data are included in the analyses were verified with histology. Data from four animals were excluded because both cannulas were implanted outside of the amygdala.

We addressed the anatomical specificity of K252a by examining the behavioral results from those animals with cannulas implanted outside of the amygdala. Analysis of cannula placements was performed in a blinded manner with respect to behavioral data. Missed placements were located rostral (caudate-putamen) and/or lateral (claustrum, dorsal endopiriform nucleus, agranular insular, or piriform cortex) to the amygdala. The behavioral effects of these placements are shown in Figure $5 C$. The difference scores of animals that received $\mathrm{K} 252 \mathrm{a}$ infusions in areas other than the amygdala (missed placements) were not significantly different from the difference scores of animals receiving ACSF infusion, suggesting that the drug effect is only seen when K252a is infused directly into the BLA. These data suggest that neurotrophin activity within the amygdala during or shortly after fear conditioning is required for the acquisition of new fear memories.

\section{Examination of TrkB function with a dominant-negative lentivirus}

The findings that BDNF is dynamically regulated and that Trk receptors are activated with fear conditioning suggested that the BDNF-specific receptor, TrkB, may be the primary Trk receptor mediating neurotrophin-dependent plasticity in this paradigm; however, there are no pharmacological methods to specifically examine TrkB function. To circumvent this limitation, we constructed a lentiviral vector that expresses a dominant-negative truncated isoform of TrkB (TrkB.T1). Lentiviral vectors (Fig. 6A) were constructed expressing $\mathrm{CDNAs}$ for either a truncated TrkB receptor or a GFP reporter. Previous studies show that a truncated TrkB receptor acts as a specific dominant-negative inhibitor of normal TrkB function (Eide et al., 1996; Saarelainen et al., 2000; Haapasalo et al., 2001).

We first verified the dominant-negative activity of TrkB.T1 by examining its ability to inhibit BDNF-induced differentiation of PC12 cells in culture. The rat pheochromocytoma cell line, PC12, is normally unresponsive to BDNF. It has been shown that transfection of this cell line with TrkB.FL confers BDNF-responsive differentiation in vitro (Squinto et al., 1991; Nakatani et al., 1998). 
A

\section{Vector Constructs}

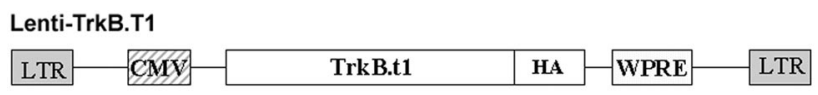

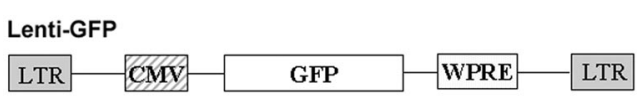

B

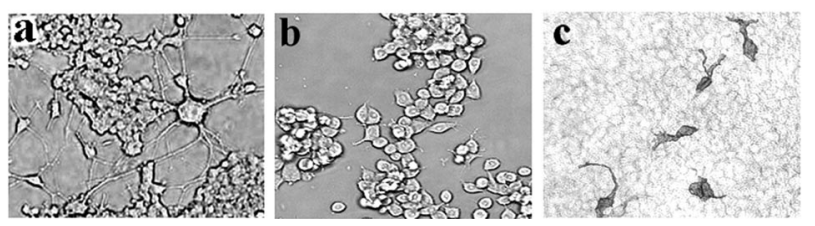

Figure 6. In vitro analysis of lenti-TrkB.T1. A, Schematic representation of lentiviral vector constructs. Lenti-TrkB.T1 and lenti-GFP vectors were constructed downstream of the CMV promoter. The lenti-TrkB.T1 vector construct contained an HA-tagged TrkB.T1 gene. The lenti-GFP construct contained a reporter gene encoding GFP. LTR, Long terminal repeat; WPRE, woodchuck hepatitis virus posttranscriptional regulatory element. $B a, P C 12$ cells transfected with TrkB.FL after exposure to BDNF. Bb, PC12 cells cotransfected with TrkB.FL plus TrkB.T1 after exposure to BDNF. Bc, Immunocytochemical analysis of HA immunoreactivity in HEK293T cells infected with lenti-TrkB.T1 virus.

In this study, PC12 cells were transfected with TrkB.FL alone (PC12-TrkB), TrkB.T1 alone, or cotransfected with TrkB.FL plus GFP, or TrkB.FL plus TrkB.T1. Cells were subsequently exposed to BDNF, and the number of differentiated cells was counted in each well. Using this in vitro assay, we also assessed the ability of K252a to inhibit BDNF-induced differentiation.

Cells transfected with TrkB.FL and exposed to BDNF exhibit differentiation as demonstrated by enhanced process outgrowth (Fig. 6 $\mathrm{Ba}$ ). This same degree of differentiation is seen when cells are cotransfected with TrkB.FL plus GFP and exposed to BDNF (data not shown). In contrast, cells cotransfected with TrkB.FL plus TrkB.T1 exhibited significantly reduced differentiation and process outgrowth in response to BDNF (Fig. $6 \mathrm{Bb}$ ). When cells are transfected with TrkB.T1 alone, we observed no cytotoxicity, suggesting that TrkB.T1 by itself is not detrimental to cell viability (data not shown). Quantitative analysis revealed significant changes in the number of differentiated cells across treatment groups (average number of differentiated cells counted per field: TrkB.FL + BDNF $=378$, TrkB.FL + TrkB.T1 + BDNF $=156$, TrkB.FL + BDNF + K252a $=165)\left(\right.$ ANOVA: $F_{(2,13)}=21.4 ; p<$ 0.05 ). A post hoc multiple-comparisons (Tukey's) test found a significant difference between the TrkB.FL alone and TrkB.FL plus TrkB.T1 group $(p \leq 0.01)$. These results indicate that expression of TrkB.T1 has a dominant-negative effect on BDNFmediated signaling. In addition, the post hoc Tukey's test also found a significant difference between the TrkB.FL alone and the TrkB.FL plus K252a group ( $p \leq 0.01$ ), suggesting that both TrkB.T1 and K252a can inhibit the ability of TrkB to respond to BDNF.

To assess the in vitro infection capability of lenti-TrkB.T1 and to examine the ability of HA-epitope tag immunostaining to detect TrkB.T1-infected cells, HEK293T cells were exposed to lentiTrkB.T1 and examined $48 \mathrm{hr}$ later. Infected cells were visualized using immunohistochemistry with an HA antibody to detect TrkB.T1. Figure $6 B c$ demonstrates infection of cultured HEK293 cells with the lenti-TrkB.T1 virus, confirming that our lentivirus efficiently infects cells in vitro and the transduced HA-tagged TrkB.T1 protein can be detected using immunohistochemistry.

\section{Lentiviral vector expression in vivo}

Animals were infected with high-titer stocks $\left(3 \times 10^{7}-7 \times 10^{7}\right.$ $\mathrm{TU} / \mathrm{ml}$ ) of lenti-TrkB.T1 and lenti-GFP virus and killed after behavioral procedures (described below). Brains were processed with immunohistochemistry to detect the presence of TrkB.T1 and GFP. We found a large number of GFP-positive cells in the amygdala of lenti-GFP infected rats (Fig. 7a) indicating that cells in the amygdala were successfully infected with this lentivirus. Rats infected with lenti-TrkB.T1 showed a large number of HApositive cells in the amygdala, further confirming the in vivo infectability of our viral vectors (Fig. $7 d$ ). Cresyl violet analysis of parallel sections revealed no pathological change in the infected areas of the brain (Fig. $7 b, e$ ), confirming the ability of our lentiviral vectors to safely infect neurons in vivo. Additionally, highpower examination of regions with lower-density infections revealed that the lentivirus expressing GFP and TrkB.T1 is indeed infecting individual neurons within these regions (Fig. $7 c, f$ ).

\section{Expression of TrkB.T1 in the amygdala impairs acquisition of fear conditioning}

To examine the role of TrkB receptors in amygdala-dependent learning and memory, lenti-TrkB.T1 was used to express truncated $\mathrm{TrkB}$ receptors in the amygdala. Animals received bilateral infusions of lenti-TrkB.T1 or lenti-GFP into the basolateral amygdala 2 weeks before training. This allowed sufficient time for the viral vectors to infect neuronal cells within the amygdala. Animals were trained and tested as outlined in Figure 8 A (Acquisition Experiment). Infusion of lenti-TrkB.T1 resulted in an impairment in fear learning when animals were tested $48 \mathrm{hr}$ after the last training session. Mean startle amplitude on startle-alone and light-startle test trials and the difference between these two trial types are shown for each group in Figure $8 \mathrm{~B}$. Mean difference scores of lenti-TrkB.T1-infected animals were significantly lower than difference scores of GFP-infected animals ( $t$ test; ${ }^{\star} p \leq 0.05$ ). This difference was not accounted for by a change in the startlealone trials because there was no significant difference between groups on the startle-alone trials.

\section{Lenti-TrkB.T1 virus demonstrates anatomical specificity}

To address the anatomical specificity of lenti-TrkB.T1, we examined the behavioral results from those animals with TrkB.T1 infection outside of the amygdala. Analysis of viral infection sites was performed in a blinded manner with respect to behavioral data. Data from four animals were excluded from the two experiments described above because of TrkB.T1 infection outside of the amygdala as determined by immunohistochemical analysis. Missed placements were located primarily dorsal (caudate-putamen) to the amygdala. The behavioral effects of these placements are shown in Figure $8 C$. The mean difference scores of animals that received lenti-TrkB.T1 infusions in areas other than the amygdala (missed placements) were significantly greater than the difference scores of animals receiving lenti-TrkB.T1 directly into the amygdala ( $t$ test; ${ }^{\star} p \leq 0.01$ ) (Fig. $8 C$ ) and not significantly different from lenti-GFP-infused rats with BLA placements. These data suggest that the effects of lenti-TrkB.T1 are only seen when the virus is infused directly into the amygdala and indicates that the attenuation of fear learning by lenti-TrkB.T1 exhibits anatomical specificity. 

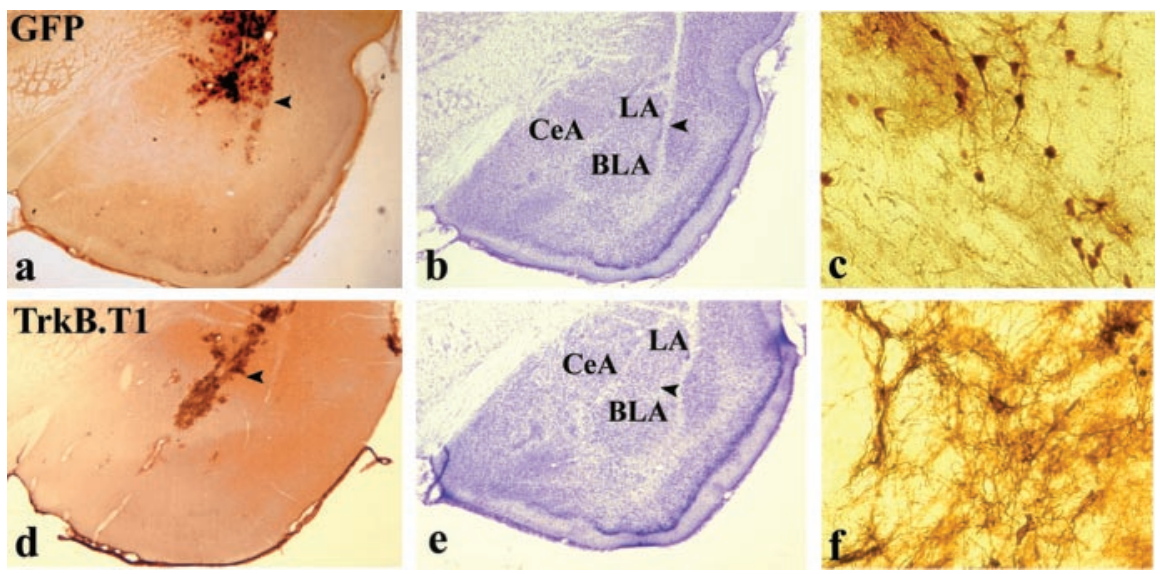

Figure 7. Lentiviral expression in vivo. Animals were infected with lentiviral vectors and killed 3 weeks later. $a, d$, Coronal sections through the amygdala showing lenti-GFP or lenti-TrkB.T1 virus infection as detected by immunohistochemistry using antibodies against GFP or HA. b, e, Cresyl violet staining of parallel sections showing the absence of neuronal damage in infected regions. Arrows indicate regions infected with lentivirus. $c$, $f$, High-powered magnification $(40 \times)$ of other regions with lowerdensity infection, demonstrating that lentivirus infects individual neurons. CeA, Central amygdala; LA, lateral amygdala; BLA, basolateral amygdala.

A
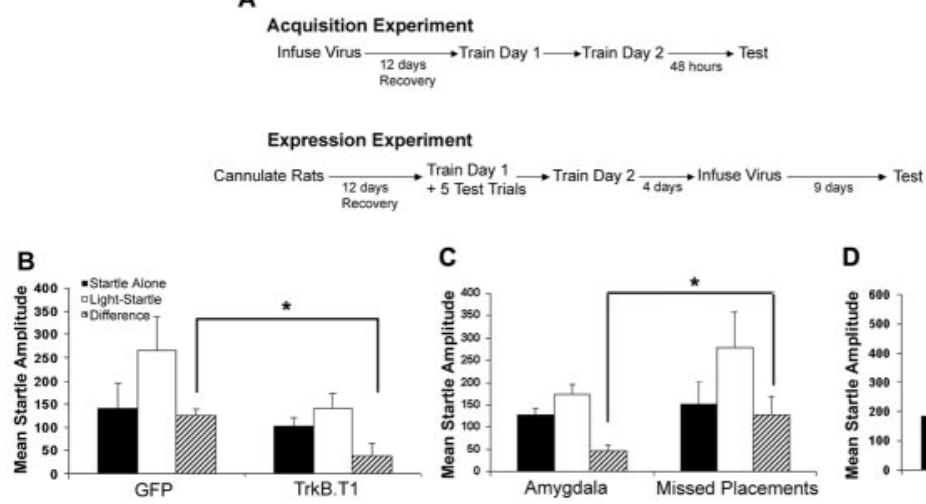

Figure 8. Effect of lentiviral induced expression of TrkB.T1 in the amygdala on fear conditioning as assessed by fearpotentiated startle. $A$, Outline of behavioral paradigms for acquisition and expression experiments. $B$, Filled bars represent startle response to startle-alone trials, white bars represent startle response to light-startle trials, and hatched bars represent difference scores. Mean startle amplitude \pm SEM on startle-alone trials, light-startle trials, and the difference between the two are shown for animals receiving lentivirus infusion into the amygdala. Mean difference scores of lenti-TrkB.T1-infused animals were significantly lower than difference scores of lenti-GFP-infused animals ( $t$ test; ${ }^{*} p<0.05$ ). C, Anatomical specificity of TrkB.T1. Mean startle amplitude \pm SEM on startle-alone trials, light-startle trials, and the difference between the two are shown for animals receiving infusion of TrkB.T1 into the amygdala or areas outside the amygdala (missed placements). Mean difference scores for missed placement animals were significantly higher than difference scores of animals infused with lenti-TrkB.T1 into the amygdala ( $t$ test; ${ }^{*} p<0.01$ ), demonstrating that the virus must be present within the amygdala to impair fear learning. $D$, Effect of amygdala infection with lenti-TrkB.T1 on the expression of fear-potentiated startle. Animals were trained, infected, and tested as in $A$. When TrkB.T1 virus is present during expression, but not acquisition, of fear learning, there is no difference between fear-potentiated startle with lenti-TrkB.T1 animals compared with lenti-GFP animals. An ANOVA with repeated measures showed a significant fear-potentiated startle effect-by-trial type but no trial-by-group interaction (ANOVA; $p \leq 0.05$ ).

TrkB.T1 in the amygdala does not block expression of fear

In the experiments described above, all animals were infected with lenti-TrkB.T1 or lenti-GFP virus before acquisition of fear conditioning. Because these lentiviral vectors stably infect neurons in vivo, amygdala neurons are still infected with virus during fearpotentiated startle testing. Lentiviral-induced expression of TrkB.T1 neurons cannot be reversed before testing; thus there was no way to determine whether our observed deficit in fear conditioning was a result of impaired acquisition of fear conditioning or possibly impaired expression of fear-potentiated startle. To discriminate between these two possibilities, animals had to be trained virus free and then injected with lentivirus before testing. To accomplish this,

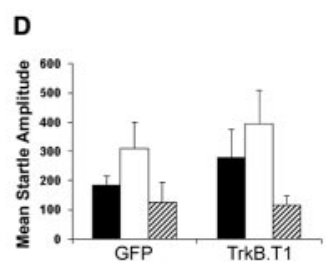

another set of animals was cannulated before the start of this experiment such that the virus could be infused directly into the amygdala after training but before testing, without surgical intervention after training. This experiment is outlined in Figure 8 A (Expression Experiment).

Briefly, after recovery from cannulation, all animals were trained over $2 \mathrm{~d}$, and a brief fear test was performed after the first training session. On the basis of these preinfection test results, rats were assigned to treatment groups such that each group (lenti-TrkB.T1 and lenti-GFP) had comparable mean levels of fear-potentiated startle. Four days after training, animals were infused with lentiTrkB.T1 or lenti-GFP virus and tested $9 \mathrm{~d}$ later. This allowed sufficient time for optimal viral infection and transgene expression as determined by preliminary immunohistochemistry analysis in our laboratory as well as previous published literature (Naldini et al., 1996b; Ehrengruber et al., 2001; Fleury et al., 2003). An ANOVA with repeated measures showed a significant fear-potentiated startle effect by trial type $\left(F_{(1,21)}=11.2 ; p \leq\right.$ 0.05 ), but no trial-by-group interaction (Fig. $8 D)$. These results indicate that collapsed across groups, all animals showed fearpotentiated startle. To evaluate whether viral infection affected expression of fear-potentiated startle, we compared preinfection test difference scores with postinfection test difference scores. A two-way ANOVA showed no group $\left(\mathrm{GFP}\right.$ vs TrkB.T1) $\left(F_{(1,21)}=0.01 ; p>\right.$ $0.5)$ or session (pretest vs post-test) $\left(F_{(1,21)}=0.005 ; p>0.5\right)$ effect, nor a significant group-by-session interaction $\left(F_{(1,21)}=0.001 ; p>0.5\right)$.

These data demonstrate that TrkB.T1 did not disrupt expression or performance of fear-potentiated startle; rather, theimpairments observed in Figure 8, $B$ and $C$, are attributable to an apparent requirement for TrkB function during the acquisition or consolidation of fear conditioning. Animals were killed shortly after these behavioral experiments, and viral infection was confirmed with immunohistochemistry.

\section{Discussion}

In summary, our data support a role for BDNF and TrkB signaling within the amygdala during fear conditioning. We have shown that BDNF mRNA is elevated temporarily during the period after fear conditioning and that this increase occurs independent of the sensory modality of the conditioned stimulus. In comparison, NGF, NT4/5, NT3, aFGF, and bFGF mRNAs were not induced in the amygdala with this manipulation. Evidence for neurotrophin release during this period was shown by increased levels of phosphorylated Trk receptors after fear learning. Blockade of Trk receptor signaling with K252a impaired fear con- 
ditioning. Finally, a specific role for the BDNF receptor, TrkB, was demonstrated by infecting neurons in the amygdala with a lentiviral vector expressing a dominant-negative $\operatorname{TrkB}$ receptor that specifically impaired acquisition, but not expression, of fear learning. This is the first study to use lentiviral vectors to impair TrkB receptor function and, as such, provides the first evidence for neurotrophin signaling in general and BDNF activation of the TrkB receptors in particular in the acquisition or consolidation of conditioned fear in the amygdala.

We found that BDNF mRNA expression was induced in the basolateral amygdala $2 \mathrm{hr}$ after fear conditioning, whereas levels of several other trophic factors did not change. The use of in situ hybridization as a quantitative measure of gene induction is well established (Hammarberg et al., 2000; Ressler et al., 2002; Sugiyama et al., 2003). These results are consistent with a number of studies that report a selective induction of BDNF expression in the hippocampus during contextual and spatial learning (Kesslak et al., 1998; Hall et al., 2000; Schaaf et al., 2001). This is the first demonstration that BDNF may have a similar role in amygdaladependent learning and memory. We also examined the BDNF receptor, TrkB, which we found to be present in abundance within the BLA. Elevated levels of phosphorylated Trk receptor, using a phospho-Trk Ab, were seen in the amygdala $2 \mathrm{hr}$ after fear conditioning, suggesting that Trk receptors are activated in the amygdala subsequent to associative CS-US pairings.

These biochemical changes suggested a role for BDNF in amygdala-dependent learning and memory processes, but they are only correlational in nature. Previous studies implicating a role for BDNF and TrkB in learning and memory processes have used knock-out or transgenic animal models, in which animals deficient in BDNF or TrkB demonstrate impaired learning and memory abilities (Linnarsson et al., 1997; Minichiello et al., 2002); however, BDNF knock-out animals do not survive through adulthood and thus BDNF heterozygous animals must be used (Minichiello et al., 2002). Regional specificity is also a major limitation for both knock-out and transgenic approaches. Moreover, it is impossible to evaluate the role of BDNF in learning versus performance in these knock-out mice because gene levels are reduced during both training and testing. Some of these obstacles have been overcome with gene-targeted mice, in which knock-out of the gene occurs conditionally only during postnatal development (Minichiello et al., 2002). Although this approach addresses the issues of developmental lethality, it only partially addresses the issues of regional specificity and does not address issues of acquisition versus expression.

To more definitively reveal a role for BDNF activation of the TrkB receptor in mediating these processes, we sought to show a behavioral impairment in amygdala-dependent learning and memory after disruption of signaling using both a pharmacologic and a genetic approach. Intra-amygdala infusions of the pharmacological Trk inhibitor K252a significantly impaired fear conditioning; however, because $\mathrm{K} 252 \mathrm{a}$ is not specific to the TrkB receptor, we also used a lentiviral vector to express a dominant-negative TrkB receptor in the amygdala. Dominant-negative inhibition of TrkB within the amygdala, caused by lentiviral-mediated TrkB.T1 expression, impaired fear-conditioned learning without disrupting baseline amygdala function. The anatomical specificity of this viral manipulation was demonstrated by examining the extra-amygdala missed placements from this experiment. Animals with TrkB.T1 infection in areas outside the amygdala showed no impairment in fear conditioning and demonstrated significantly greater fear-potentiated startle when compared with animals with TrkB.T1 infection in the amygdala. These results demonstrate that expression of TrkB.T1 specifi- cally within the amygdala impairs fear conditioning and suggests a requirement for TrkB signaling in the acquisition and consolidation of fear memory. Activation of the TrkB receptor does not appear to be required for normal amygdala function and expression of fear; rather, it may be necessary only during acquisition of new learning.

Additional studies using lentiviral vectors to express BDNF and full-length TrkB separately and in combination with other modulators of neural plasticity will allow us to further elucidate the role of this neurotrophin within the amygdala. In addition, development of inducible lentiviral vectors in which the expression of the transgene can be closely regulated will provide further temporal control over neurotrophin activity. A particularly useful application of this approach will be in attempting to uncover whether BDNF is acting presynaptically (Zakharenko et al., 2003), postsynaptically (Caleo et al., 2000), or via an autoreceptor mechanism (Pitts and Miller, 2000).

What are the mechanisms of BDNF- and TrkB-related plasticity within the amygdala? Until now, mechanisms of neural plasticity within the amygdala have focused primarily on glutamate receptors (GluRs): AMPA, metabotropic GluRs (mGluRs), and most notably the NMDA receptor (Miserendino et al., 1990; Huang and Kandel, 1998; Schafe et al., 2001; Walker and Davis, 2002). There is increasing evidence that TrkB-dependent mechanisms of neural plasticity act in parallel with mGluR and NMDA-dependent mechanisms in many neuronal cell types (Black, 1999; Canossa et al., 2001; Gewirtz et al., 2002). Recent work has shown that TrkB is a powerful regulator of phosphatidylinositol 3 kinase (PI3K) (Atwal et al., 2000), a critical intracellular mediator required for synaptic plasticity during fear conditioning (Lin et al., 2001). Although the focus at that time was on the possible mechanisms of NMDA and $\mathrm{Ca}^{2+}$-channel activation of PI3K, it is quite likely that BDNF activation of TrkB is a critical step in PI3K-mediated signaling within the amygdala. Furthermore, BDNF activation of TrkB appears to increase NMDA function and open probability time (Levine et al., 1998). The fact that we see significant but not complete blockade of fear learning suggests that other intracellular cascades likely act in parallel with those activated by BDNF to mediate long-term fear conditioning. Future studies will examine the differential roles of NMDAversus TrkB-dependent plasticity events within the amygdala as well as the interactions between the different intracellular pathways activated by these receptors.

Calcium channels, specifically the L-type voltage-dependent calcium channels, have recently been implicated in synaptic plasticity underlying fear conditioning (Weisskopf et al., 1999). Within the hippocampus, phospholipase C (PLC) activation of the $\mathrm{Na}^{+}$- and $\mathrm{Ca}^{2+}$-conducting transient receptor potential channel channels has been shown to play an important role in synaptic plasticity (Kim et al., 2003). Contextual fear memory formation has been shown to involve PLC within the hippocampus (Weeber et al., 2001). Furthermore, BDNF activates a cationic influx in pontine neurons through the PLC-dependent opening of a TRPC3 channel (Li et al., 1999). Despite this intriguing data, PLC and TRPC activation within the amygdala remain unexamined in the acquisition or consolidation of fear memory formation.

Mitogen-activated protein kinase (MAPK) within the amygdala is required for fear memory formation and extinction of fear (Schafe et al., 2000; Lu et al., 2001), presumably through activation of the NMDA receptor. Recently BDNF activation of TrkB has been shown to mediate translocation of activated MAPK to the nucleus (Patterson et al., 2001). Thus, BDNF release may be required for the activation of cAMP response element-binding 
protein (CREB) within the amygdala (Impey et al., 1998; Josselyn et al., 2001) that is necessary for fear learning. The convergent roles of NMDA and TrkB receptor activation on MAPK and CREB intracellular signaling likely lead to transcriptional (Ressler et al., 2002) as well as translational (Schafe et al., 1999) mechanisms of synaptic plasticity after fear conditioning.

Further elucidation of BDNF- and TrkB-mediated signaling within the amygdala should provide novel insights into the mechanisms of synaptic plasticity that underlies fear conditioning.

\section{References}

Atwal JK, Massie B, Miller FD, Kaplan DR (2000) The TrkB-Shc site signals neuronal survival and local axon growth via MEK and P13-kinase. Neuron 27:265-277.

Barde YA, Davies AM, Johnson JE, Lindsay RM, Thoenen H (1987) Brain derived neurotrophic factor. Prog Brain Res 71:185-189.

Barnes CA (1995) Involvement of LTP in memory: are we "searching under the street light"? Neuron 15:751-754.

Black IB (1999) Trophic regulation of synaptic plasticity. J Neurobiol 41:108-111.

Caleo M, Menna E, Chierzi S, Cenni MC, Maffei L (2000) Brain-derived neurotrophic factor is an anterograde survival factor in the rat visual system. Curr Biol 10:1155-1161.

Canossa M, Gartner A, Campana G, Inagaki N, Thoenen H (2001) Regulated secretion of neurotrophins by metabotropic glutamate group I (mGluRI) and Trk receptor activation is mediated via phospholipase C signaling pathways. EMBO J 20:1640-1650.

Cassella JV, Harty TP, Davis M (1986) Fear conditioning, prepulse inhibition and drug modulation of a short latency startle response measured electromyographically from neck muscles in the rat. Physiol Behav 36:1187-1191.

Davis M (1992) The role of the amygdala in fear and anxiety. Annu Rev Neurosci 15:353-375.

Ehrengruber MU, Hennou S, Bueler H, Naim HY, Deglon N, Lundstrom K (2001) Gene transfer into neurons from hippocampal slices: comparison of recombinant Semliki Forest Virus, adenovirus, adeno-associated virus, lentivirus, and measles virus. Mol Cell Neurosci 17:855-871.

Eide FF, Vining ER, Eide BL, Zang K, Wang XY, Reichardt LF (1996) Naturally occurring truncated trkB receptors have dominant inhibitory effects on brain-derived neurotrophic factor signaling. J Neurosci 16:3123-3129.

Fanselow MS, LeDoux JE (1999) Why we think plasticity underlying Pavlovian fear conditioning occurs in the basolateral amygdala. Neuron 23:229-232.

Fleury S, Simeoni E, Zuppinger C, Deglon N, von Segesser LK, Kappenberger L, Vassalli G (2003) Multiply attenuated, self-inactivating lentiviral vectors efficiently deliver and express genes for extended periods of time in adult rat cardiomyocytes in vivo. Circulation 107:2375-2382.

Gewirtz JC, Chen AC, Terwilliger R, Duman RC, Marek GJ (2002) Modulation of DOI-induced increases in cortical BDNF expression by group II mGlu receptors. Pharmacol Biochem Behav 73:317-326.

Haapasalo A, Koponen E, Hoppe E, Wong G, Castren E (2001) Truncated trkB.T1 is dominant negative inhibitor of trkB.TK+-mediated cell survival. Biochem Biophys Res Commun 80:1352-1358.

Hall J, Thomas KL, Everitt BJ (2000) Rapid and selective induction of BDNF expression in the hippocampus during contextual learning. Nat Neurosci 3:533-535.

Hammarberg H, Piehl F, Risling M, Cullheim S (2000) Differential regulation of trophic factor receptor mRNAs in spinal motoneurons after sciatic nerve transection and ventral root avulsion in the rat. J Comp Neurol 426:587-601.

Huang YY, Kandel ER (1998) Postsynaptic induction and PKA-dependent expression of LTP in the lateral amygdala. Neuron 21:169-178.

Impey S, Smith DM, Obrietan K, Donahue R, Wade C, Storm DR (1998) Stimulation of cAMP response element (CRE)-mediated transcription during contextual learning. Nat Neurosci 1:595-601.

Jiang B, Akaneya Y, Ohshima M, Ichisaka S, Hata Y, Tsumoto T (2001) Brain-derived neurotrophic factor induces long-lasting potentiation of synaptic transmission in visual cortex in vivo in young rats, but not in the adult. Eur J Neurosci 14:1219-1228.

Jing S, Tapley P, Barbacid M (1992) Nerve growth factor mediates signal transduction through trk homodimer receptors. Neuron 6:1067-1079.
Josselyn SA, Shi C, Carlezon Jr WA, Neve RL, Nestler EJ, Davis M (2001) Long-term memory is facilitated by cAMP response element-binding protein overexpression in the amygdala. J Neurosci 21:2404-2412.

Katz LC, Shatz CJ (1996) Synaptic activity and the construction of cortical circuits. Science 274:1133-1138.

Kesslak JP, So V, Choi J, Cotman CW, Gomez-Pinilla F (1998) Learning upregulates brain-derived neurotrophic factor messenger ribonucleic acid: a mechanism to facilitate encoding and circuit maintenance? Behav Neurosci 112:1012-1019.

Kim SJ, Kim YS, Yuan JP, Petralia RS, Worley PF, Linden DJ (2003) Activation of the TRPC1 cation channel by metabotropic glutamate receptor mGluR1. Nature 426:285-291.

Klein R, Nanduri V, Jing SA, Lamballe F, Tapley P, Bryant S, Cordon-Cardo C, Jones KR, Reichardt LF, Barbacid M (1991) The trkB tyrosine protein kinase is a receptor for brain-derived neurotrophic factor and neurotrophin-3. Cell 66:395-403.

Knusel B, Hefti F (1992) K252a compounds: modulators of neurotrophin signal transduction. J Neurochem 59:1987-1996.

LeDoux JE (2000) Emotion circuits in the brain. Annu Rev Neurosci 23:155-184.

Leibrock J, Lottspeich F, Hohn A, Hofer M, Hengerer B, Masiakowski P, Thoenen H, Barde YA (1989) Molecular cloning and expression of brain-derived neurotrophic factor. Nature 341:149-152.

Levine ES, Crozier RA, Black IB, Plummer MR (1998) Brain-derived neurotrophic factor modulates hippocampal synaptic transmission by increasing $N$-methyl-D-aspartic acid receptor activity. Proc Natl Acad Sci USA 95:10235-10239.

Li HS, Xu XZ, Montell C (1999) Activation of a TRPC3-dependent cation current through the neurotrophin BDNF. Neuron 24:261-273.

Lin CH, Yeh SH, Lu KT, Leu TH, Chang WC, Gean PW (2001) A role for the PI-3 kinase signaling pathway in fear conditioning and synaptic plasticity in the amygdala. Neuron 31:841-851.

Linnarsson S, Bjorklund A, Ernfors P (1997) Learning deficit in BDNF mutant mice. Eur J Neurosci 9:2581-2587.

Lu KT, Walker DL, Davis M (2001) Mitogen-activated protein kinase cascade in the basolateral nucleus of amygdala is involved in extinction of fear-potentiated startle. J Neurosci 21:RC162(1-5).

Maren S (2001) Neurobiology of Pavlovian fear conditioning. Annu Rev Neurosci 24:897-931.

McAllister AK, Katz LC, Lo DC (1999) Neurotrophins and synaptic plasticity. Annu Rev Neurosci 22:295-318.

McGaugh JL (2002) Memory consolidation and the amygdala: a systems perspective. Trends Neurosci 25:456.

Middlemas DS, Lindberg RA, Hunter T (1991) trkB, a neural receptor protein-tyrosine kinase: evidence for a full-length and two truncated receptors. Mol Cell Biol 11:143-153.

Minichiello L, Calella AM, Medina DL, Bonhoeffer T, Klein R, Korte M (2002) Mechanism of TrkB-mediated hippocampal long-term potentiation. Neuron 36:121-137.

Miserendino MJ, Sananes CB, Melia KR, Davis M (1990) Blocking of acquisition but not expression of conditioned fear-potentiated startle by NMDA antagonists in the amygdala. Nature 345:716-718.

Nakatani A, Yamada M, Asada A, Okada M, Ikeuchi T, Hatanaka H (1998) Comparison of survival-promoting effects of brain-derived neurotrophic factor and neurotrophin-3 on PC12h cells stably expressing TrkB receptor. J Biochem (Tokyo) 123:707-717.

Naldini L, Blomer U, Gage FH, Trono D, Verma IM (1996a) Efficient transfer, integration, and sustained long-term expression of the transgene in adult rat brains injected with a lentiviral vector. Proc Natl Acad Sci USA 93:11382-11388.

Naldini L, Blomer U, Gallay P, Ory D, Mulligan R, Gage FH, Verma IM, Trono D (1996b) In vivo gene delivery and stable transduction of nondividing cells by a lentiviral vector. Science 272:263-267.

Paschall GY, Davis M (2002) Olfactory-mediated fear-potentiated startle. Behav Neurosci 116:4-12.

Patterson SL, Pittenger C, Morozov A, Martin KC, Scanlin H, Drake C, Kandel ER (2001) Some forms of cAMP-mediated long-lasting potentiation are associated with release of BDNF and nuclear translocation of phospho-MAP kinase. Neuron 32:123-140.

Paxinos G, Watson C (1997) The rat brain in stereotaxic coordinates, Ed 3. New York: Academic.

Phillips RG, LeDoux JE (1992) Differential contribution of amygdala and 
hippocampus to cued and contextual fear conditioning. Behav Neurosci 106:274-285.

Pitts AF, Miller MW (2000) Expression of nerve growth factor, brainderived neurotrophic factor, and neurotrophin-3 in the somatosensory cortex of the mature rat: coexpression with high-affinity neurotrophin receptors. J Comp Neurol 418:241-254.

Poo MM (2001) Neurotrophins as synaptic modulators. Nat Rev Neurosci 2:24-32.

Ressler KJ, Paschall G, Zhou XL, Davis M (2002) Regulation of synaptic plasticity genes during consolidation of fear conditioning. J Neurosci 22:7892-7902.

Saarelainen T, Lukkarinen JA, Koponen S, Grohn OH, Jolkkonen J, Koponen E, Haapasalo A, Alhonen L, Wong G, Koistinaho J, Kauppinen RA, Castren E (2000) Transgenic mice overexpressing truncated trkB neurotrophin receptors in neurons show increased susceptibility to cortical injury after focal cerebral ischemia. Mol Cell Neurosci 16:87-96.

Sassoon DA, Garner I, Buckingham M (1988) Transcripts of alpha-cardiac and alpha-skeletal actins are early markers for myogenesis in the mouse embryo. Development 104:155-164.

Schaaf MJ, Workel JO, Lesscher HM, Vreugdenhil E, Oitzl MS, de Kloet ER (2001) Correlation between hippocampal BDNF mRNA expression and memory performance in senescent rats. Brain Res 915:227-233.

Schafe GE, Nader NV, Sullivan GM, Harris A, LeDoux JE (1999) Memory consolidation for contextual and auditory fear conditioning is dependent on protein synthesis, PKA, and MAP kinase. Learn Mem 6:97-110.

Schafe GE, Atkins CM, Swank MW, Bauer EP, Sweatt JD, LeDoux JE (2000) Activation of ERK/MAP kinase in the amygdala is required for memory consolidation of Pavlovian fear conditioning. J Neurosci 20:8711-8787.

Schafe GE, Nader K, Blair HT, LeDoux JE (2001) Memory consolidation of Pavlovian fear conditioning: a cellular and molecular perspective. Trends Neurosci 24:540-546.

Squinto SP, Stitt TN, Aldrich TH, Davis S, Bianco SM, Radziejewski C, Glass DJ, Masiakowski P, Furth ME, Valenzuela DM (1991) trkB encodes a functional receptor for brain-derived neurotrophic factor and neurotrophin-3 but not nerve growth factor. Cell 65:885-893.

Sugiyama N, Kanba S, Arita J (2003) Temporal changes in the expression of brain-derived neurotrophic factor mRNA in the ventromedial nucleus of the hypothalamus of the developing rat brain. Brain Res Mol Brain Res 115:69-77.

Tapley P, Lamballe F, Barbacid M (1992) K252a is a selective inhibitor of the tyrosine protein kinase activity of the trk family of oncogenes and neurotrophin receptors. Oncogene 7:371-381.

Thoenen H (1995) Neurotrophins and neuronal plasticity. Science 270:593-598.

Walker DL, Davis M (2000) Involvement of $N$-methyl-D-aspartate (NMDA) receptors within the amygdala in short- versus long-term memory for fear conditioning as assessed with fear-potentiated startle. Behav Neurosci 114:1019-1033.

Walker DL, Davis M (2002) The role of amygdala glutamate receptors in fear learning, fear-potentiated startle, and extinction. Pharmacol Biochem Behav 71:379-392.

Weeber EJ, Savage DD, Sutherland RJ, Caldwell KK (2001) Fear conditioning-induced alterations of phospholipase C-beta la protein level and enzyme activity in rat hippocampal formation and medial frontal cortex. Neurobiol Learn Mem 76:151-182.

Weisskopf MG, Bauer EP, LeDoux JE (1999) L-type voltage-gated calcium channels mediate NMDA-independent associative long-term potentiation at thalamic input synapses to the amygdala. J Neurosci 19:10512-10519.

Zakharenko SS, Patterson SL, Dragatsis I, Zeitlin SO, Siegelbaum SA, Kandel ER, Morozov A (2003) Presynaptic BDNF required for a presynaptic but not postsynaptic component of LTP at hippocampal CA1-CA3 synapses. Neuron 39:975-990.

Zufferey R, Donello JE, Trono D, Hope TJ (1999) Woodchuck hepatitis virus posttranscriptional regulatory element enhances expression of transgenes delivered by retroviral vectors. J Virol 73:2886-2892. 